\title{
Research on Teaching Reform of Database System Principle Course
}

\author{
Yangqing Zhu \\ Electronic and Information Engineering School \\ Foshan University \\ Foshan, China \\ Email: zhuyangqing_830516@163.com
}

\begin{abstract}
The technology of Internet of Things has been applied to every aspect of society. Data storage technology of Internet of Things was also constantly updated and developed, has formed relational database and non-relational database technology. At present, Chinese universities database system principle course mainly used the relational database technology as the teaching content. In the teaching mode, teachers were the core of teaching, and teaching evaluation was mainly based on the final examination. These were not conducive to the development of the course teaching, which was not conducive to the cultivation of the applied talents. Based on the analysis of the present teaching situation of the course of the database system principles, this paper discussed the reform ideas of the course of the database system principle combining the development of the new database technology and the actual technical requirements of the talents, and provided a reference scheme for the training of the latest database technology personnel.
\end{abstract}

Keywords: Internet of Things; Database System Principle; Teaching Reform; Application Talents Training

\section{INTRODUCTION}

The rapid development of modern computer network technology has accelerated the extensive application and development of database technology. From small single transaction processing system to large information system, from online transaction to online analysis and processing, from general enterprise management to computer aided design and manufacture, computer integrated manufacturing system, e-government, electronic commerce, smart city, geographic information system, and so on, database technology has been used to store and manage information resource in more and more fields [1]. In particular, with the development of Internet and Internet of Things, the users can directly access and use the database, such as online shopping, online banking, urban traffic inquiries, intelligent navigation, and intelligent environment and so on [2]. The database has become an indispensable part of everyone's life. The principle of database system was a necessary basic course for the major of Internet of Things, computer science and technology, network engineering, software engineering and so on, it was a comprehensive course with both theory and practice [3]. It plays a connecting role in the related courses. Therefore, it is of great significance to continuously explore the teaching reform of database system principle course.

\section{ANALYSIS OF TEACHING STATUS OF DATABASE SYSTEM PRINCIPLE COURSE}

In recent years, the course of database system principle has been reforming and has made some progress. Many reform measures have been implemented in teaching content and practice, and the teaching effect has been improved. But there were still some problems.

(1) Theoretical cases and practice cases were not closely linked, leading to a lack of solid knowledge and could not be well applied to practice. At present, the teaching book of database system principle course was mainly used the Introduction to Database System to be written by Professor Wang Shan of Renmin University of China. The textbook has the advantages of solid theory and comprehensive content. However, the database used in the textbook was the teaching management system, and there were the student table, the curriculum table and the course selection table in the teaching management database. Although the database is simple and the student is easy to understand, it has a certain disconnection with the actual application of the Internet of Things engineering. In the actual project design, the students were still helpless [4].

(2) The method of assessment was not reasonable. The traditional examination method, only the final theory examination, neglects the process assessment, caused the students to memorize the relevant theoretical knowledge to cope with the examination, and the phenomenon of high score and low energy appeared, which was contrary to the goal of cultivating the applied talents of the course [5].

(3) The means of teaching were single. At present, multimedia courseware was widely used in the teaching of database system principles in the universities. In the course of teaching, teachers did not adjust the teaching methods according to the content of the course, consistently relying on courseware, resulting in classroom depression and low quality of classroom teaching.

\section{THE GOALS OF CURRICULUM REFORM}

In accordance with the training goal of applied talents in the specialty of the Internet of Things engineering, according to the requirements of the development of database technology, the new content can be constantly enriched to the teaching process, the construction and renewal of the curriculum resources were strengthened, the steps of the curriculum reform and construction of the database system principle were accelerated, and the students' analysis, solving 
and comprehensive application were trained and integrated, to cultivate database talents that meet market demand.

Specifically, at present, the course of database system principle mainly takes relational database as an example, but with the development and application of large data technology, many practical situations need not only relational database, but also non-relational database. Therefore, in the future database curriculum system design, we should consider the teaching design and implementation of relational database and non-relational database contents [6].

\section{THE MAIN TASKS OF REFORM}

The teaching of database system principle should adopt the combination of theoretical teaching and practical teaching. The curriculum reform of the database system principle should make full use of practical courses and practical cases provided by the actual enterprise of the Internet of Things, enrich the practical teaching contents, introduce the latest development of industry and technology, the latest requirements of the training of talents to the teaching process, update the teaching contents, improve the curriculum system, construct the training system of talents of quality, ability, knowledge and innovation [7].

On the basis of relational database teaching, such as the combination of Oracle, SQL Server, MySQL and other relational database management systems, should further consider how to carry out the teaching of non-relational database, such as the column database Hbase course, expand the course content of the database system principle, and train the students' large data management knowledge and ability, enable students to better adapt to the needs of social development.

In combination with enterprise projects and teachers' scientific research projects, teachers should guide students to participate in scientific research, and guide students to participate in competition activities at all levels to cultivate students' ability of application and innovation.

To strengthen the construction of the above curriculum resources, construct the syllabus, PPT and MOOC resources in accordance with the requirements of the development of database technology, and form a teaching plan to improve the teaching quality effectively. Sharing resources enables more teachers to use project results.

\section{TEACHING REFORM MEASURES}

According to the technology development and social needs of the Internet of Things, the way of co- construction between universities and enterprises can be carried out. Starting from the needs of the industry, the actual project of the enterprise can be chosen as the guidance of the course construction and teaching, the teaching task can be decomposed on the basis of the project, and the students' learning is driven by the project, teaching, learning, evaluation and innovation integration teaching path were constructed, the comprehensive ability of the students can be cultivated and the whole teaching process is close to the society, the post, the application and the students. Through teaching reform, students can design projects and accomplish projects according to practical problems, so as to achieve the goals of being competent, capable and competent [8].

Specifically, teaching reform can be carried out from the following aspects.

\section{A. Highlight the Training of Practical Ability}

The 2016 talent training plan in the Internet of Things engineering of Foshan University has determined the course of database system principle to be opened in the second semester of the sophomore. Combining the course teaching, the actual case of the company is introduced. Through case analysis and practice, should enhance students' understanding of the society and enhance the cultivation of students' practical ability. In the course design, reformed the previous case model of the teaching management system, fully consider the characteristics of the Internet of Things engineering major, and introduce the case of the Internet of Things engineering major, such as the environmental monitoring system, the intelligent shed and the intelligent logistics, so that the students can truly understand the connotation of the Internet of Things engineering. Through the design of database system to cultivate students' ability to solve practical problems.

\section{B. Reform of the Way of Curriculum Evaluation}

The previous evaluation of the database system principle course was carried out mainly in the final examination. The new scheme will be fully combined the process assessment with the final examination, the process assessment accounts for $50 \%$ of the total results, and the final examination accounts for $50 \%$ of the total results. The process assessment can be carried out in aspects of students' autonomous learning, group cooperative learning, classroom students explaining the results of network learning, teacher questioning, student discussion, student attendance, exercises, and experimental homework and so on. By strengthening the assessment of learning process, students are always in the state of active learning, so as to improve the efficiency and quality of teaching.

\section{Strengthening the Teaching of New Technology}

For the learning of non-relational database technology, there is no arrangement in the talent training plan. We can try the following two ways.

(1) In the first semester of the third year at the University, the course of non-relational database technology can be set up in the form of elective courses, such as Hbase application practice course.

(2) The teaching can be carried out in the form of network. We should fully study the content of Hbase of the non-relational database, make the teaching resources of micro class video, network teaching PPT, network test question database and so on, and publish the resources on the network teaching platform so that students can make full use of the fragmentation time to study. A weekly webcast can be carried out to solve the problems encountered in the course 
of students' learning, and guide the students to learn the new technology of the non-relational database.

\section{Cultivating Students' Creative Ability}

In combination with enterprise projects, teachers' topics or students' independent topic selection, the students should be guided to develop the actual system project, develop the students' design ability, application ability and innovation ability through the project development.

\section{E. Strengthen Teacher-Student Interaction}

Teachers-students interaction is a mutual influence between teachers and students. Previous studies have found that a comprehensive and accurate understanding is a prerequisite for positive teacher-student interaction. In terms of refinement, the characteristics of both teachers and students, such as sex, personality, ideas, self-expectations, behavior patterns and even social relations, will have a greater impact on their mutual cognition.

In the process of database system principle course teaching, the following teachers-students interaction measures were adopted.

(1) The Construction of the Teacher-Students Atmosphere in the Classroom. Before class begins, create a classroom atmosphere conducive to interaction. The classroom atmosphere refers to the general atmosphere of all kinds of psychology and society in the classroom, such as the degree of restraint, flexibility, anxiety, the control of teachers, initiative and motivation, etc. Teachers should try to make students' classroom environment safe and eliminate all kinds of psychological alerts.

(2) Case Teaching. Teachers need to choose cases with educational, typical and moderate difficulty, and then extract the research topics and relevant information contained in the case, and formulate detailed teaching plans. Students will read the case materials in detail before class, and record their ideas and thinking questions. In class, teacher will specify a student to summarize the contents of the case, then the teacher makes a brief analysis, create an open interactive atmosphere, the students put forward their own views, and even the different understandings of the debate between students, the teacher should grasp the direction and content of the whole class discussion, and provides the correct guidance and the thinking diverges to the students' reaction. The effect of classroom teaching is the initiative of students to analyze problems, and the cognition, emotion and attitude of the interactive subjects have also been positively affected [9].

(3) Modular Teaching. The curriculum structure of University of Cambridge adopts modular organization and management mode, which greatly strengthens the effective interaction between teachers and students. There is no specified textbook, students know the content through the auxiliary materials issued by the teacher before class. The teacher mainly explains the project and progress of his research in class. The teacher will demonstrate the thinking and process of research, guide the students to think actively, and organize the students to participate in the discussion and discuss their own opinions. Students can be highly involved and question the teacher's point of view.

(4) Give Full Play to the Advantages of "Internet +". Promote the construction of comprehensive network teaching platform, effectively support teachers and students to carry out interactive teaching activities online, provide teachers with online teaching support functions, such as the release of curriculum information, layout of homework, making courseware, online question answering, online testing, discussion type study and so on, from which to expand the teaching space. Provide students with network assisted learning support functions, such as browsing course guidance materials, conducting online questioning, online testing, and discussion learning, etc. [10]

\section{SUMMARY}

The technology of Internet of Things has developed rapidly and has been applied to every aspect of society. As the teaching of the underlying core storage technology for the data processing of the Internet of Things, we must closely follow the pace of the development of technology, sum up the latest technology of the database, form a teaching resource that can train the students to master the new technology quickly, and cultivate the students effectively so that the students can learn and master the new technology in time. Application to train qualified and needed talents for the society.

In developing the talent training plan, we should adjust the curriculum plan in time and incorporate the new technology into the curriculum system, so as to carry out the teaching smoothly. When the teaching plan is not arranged or the number of teaching hours is insufficient, we should make full use of the network to develop teaching.

\section{ACKNOWLEDGEMENT}

This research was supported by the cooperative project of education-production of Ministry of Education of the People's Republic of China (No.201702062005).

\section{REFERENCES}

[1] Guangliang Yu, "The Development and Application of Database Technology", Telecom World, Beijing, pp. 92-93, November 2017.

[2] Wenjiang Wang, The Application of Big Data and Internet of Things in Smart City, Telecom World, Beijing, pp. 1-2, March 2018.

[3] Changxuan Wan, Guoqiong Liao, Xiping Liu, Aihong Liu, Jinghui $\mathrm{Wu}$, "Teaching Reform of the Course of Database System Principle Oriented to Innovative Learning", Computer Education, Beijing, pp. 19-23, November 2017.

[4] Shan Wang, Shixuan Sha, "An Introduction to the Database System (Fifth Edition) “, Higher Education Press, Beijing, 2014.

[5] Yan Gao, "Teaching Reflection on the Course of Database System Principle in Applied Universities", Computer Era, Hangzhou, pp. 7678, October 2016.

[6] Zuquan Weng, Qi Zhang, "Analysis and Research of Database Technology Based on Mass Data Processing of Internet of Things", Internet of Things Technology, Xian, pp. 88-90, June 2014.

[7] Kun Yue, Jixian Zhang, Xiaobing Zhou, Murong Jiang, "Reform and Practice of the Teaching System of Database Technology and 
Application oriented to training of Research and Application Talents", Higher Education of Sciences, Lanzhou, pp. 109-113, February 2015.

[8] Junbo Wang, "Research and Reform of Application Talents Training in Internet of Things Professional", Internet of Things Technology, Xian, pp. 106-10, May 2015.
[9] Donghua Feng, Hangshao, "Reform and Practice of Database Technology Course under Case Teaching", Education Modernization, Beijing, pp. 51-52, March 2018.

[10] Lin Wang, Kangcai Chen, "Inquiry into the Teachers-Students Interaction in Network Teaching in Chinese Universities", Survey of Education, Guilin, pp. 52-54, March 2016. 